\title{
Exploration and Countermeasure of Psychological Tension Factors of Vocal Music Performers in Stage Performance
}

\author{
Li Deyong \\ Shanxi Vocational College of Art, Shanxi, China \\ International College, Krirk University, Thailand
}

Keywords: Vocal music performer, Psychological quality, Psychological regulation

\begin{abstract}
Vocal music performance is a very important major in many stage performing arts. Vocal music performers usually need professional study and stage practice with many years to stand out. However, many outstanding artistic talents in vocal music performance have often poor performance in the process of stage performance or major competitions. The reason is that from the presentation, the performance of vocal music performers on the stage requires not only superb professional and technical level, but also super psychological quality. However, how to cultivate psychological quality, is it a person's innate ability or the day after tomorrow? Can a vocal music performer have a super "big the art of power" and be able to present stage performances perfectly? This paper will analyze and discuss a series of psychological factors affecting the stage performance of vocal music performers, so as to provide vocal music performers with strong support except vocal singing techniques, and obtain a more perfect stage performance.
\end{abstract}

\section{Introduction}

Stage performing arts include many art categories. Broadly speaking, stage art includes drama, music, dance, opera, acrobatics and other arts. In terms of narrow sense, it is the art of drama. As a branch of music performance, vocal music plays an extremely important role in the art field. Vocal music performers are often the main performers in stage performances, sometimes they may be accompanied by orchestras and sometimes they may be accompanied by pianos. No matter what kind of accompaniment, the requirements and tests for singers themselves are extremely cruel and realistic. In the process of stage performance, the sound is displayed through a specific space and time, and the second creation process of the singer's main body is fleeting, and the beauty and lack of sound will be conveyed to the audience within a few minutes. Therefore, in the short stage re-creation performance process, what factors affect the normal play of vocal music performers?

\section{Analysis on psychological stress factors of vocal music performers in stage performance}

All artistic activities on the stage are related to psychological factors, and vocal music art itself is closely related to psychological activities. For example, in the process of vocal music learning, in order to get a better voice, it is often necessary for singers to develop rich imagination. Imagine that 
the voice flows forward, that the voice has a vertical pipeline, and even that the voice has a confrontational force from top to bottom. These can be said to be imagination or feelings. Some people say that vocal singing should have ideas. In fact, no matter which way of saying it, it is an activity of psychological consciousness. So why is an actor nervous when standing on the stage and facing the audience? The following assumptions are put forward:

Hypothesis 1. The singing technology is immature and the basic skills are not solid;

Hypothesis 2. Insufficient familiarity with the works;

Hypothesis 3. Lack of sufficient self-confidence;

Hypothesis 4. Emergencies

Hypothesis 5. Overburdened thoughts

Hypothesis 6. Worry about not being recognized

Hypothesis 7: Afraid of poor performance

In fact, vocal music performers need good breath support in the singing process, and the psychological tension caused by either situation will directly affect the singer's voice. Because when a person is extremely nervous, his breath is usually floating, his body is stiff, and he can't coordinate. The technique of vocal music singing just needs the coordination and unity between various organs of the body.The author conducted a questionnaire survey and interviews with freshmen and sophomores majoring in vocal music and outstanding artists with rich stage performance experience, and obtained the following data.

A total of 136 questionnaires were distributed and 136 were recovered. Through this questionnaire survey, the following data analysis is obtained. In the stage performance, $22.1 \%$ felt nervous, while only $8.8 \%$ were not nervous. $65.4 \%$ are nervous but can be controlled, and only $3.7 \%$ are nervous and uncontrollable. In the investigation of the factors causing psychological stress, the number of people who think that they lack stage experience accounts for $72.1 \%$, followed by $55.9 \%$ who are always worried about singing badly, followed by $41.9 \%$ who especially want to show their best self, and $8.8 \%$ for other reasons with the least proportion. In this very small range, there are three people who are afraid of other people's ideas because they are inferior; There are three people because of their appearance; Another two people have stage fright since childhood. In the survey on whether it is necessary to get a solution to the stage tension, $48.5 \%$ of people think that it is good to participate in more performances; Secondly, 26.5\% want to have some support, and $22.1 \%$ urgently need some solutions to the stage tension.

Through the analysis and statistics of the questionnaire survey, the previous assumptions are basically valid. It's just that the proportion of various stress factors varies. Most people will feel more or less nervous when performing on stage. How to overcome these "psychological barriers"? The author interviewed some excellent local artists, and through the exchange and discussion with artists, the author found that most excellent artists showed their talent in performance from an early age, and they appeared on stage earlier. Most of them were not nervous when they took the stage for the first time. They thought that this should belong to "newborn calves are not afraid of tigers". However, after embarking on a truly professional artistic road, sometimes they will feel a little nervous, especially in such occasions as unit business assessment and competition. But if you face the audience, you won't be nervous. The more the audience, the more relaxed you will be. In the questionnaire for students, many students are nervous because they are afraid of singing badly, and want to be nervous in order to express a particularly good self. In fact, these psychology are exactly the same as the occasional tension of artists. Therefore, how should we overcome the tension in the stage performance? 


\section{Stage tension relief strategies of vocal music performers}

Based on the artists' views, the following suggestions can be given:

1) First of all, we must lay good and solid basic skills;

2) Be fully prepared for the works and be aware of them (this is almost the consensus of all artists);

3)Create all opportunities to perform on stage, regardless of the size of the stage, practice more and exercise more;

4) Use deep inhalation and slow exhalation to relieve temporary tension and pressure;

5) Don't have too many distractions;

6) Think more about the music content to be expressed in the works and devote yourself to emotional expression;

The above suggestions are the truest stage experiences and feelings of many artists, which can be said to be first-hand valuable information. In fact, the performance activities of vocal music performance majors in the specific environment of stage are inseparable from our psychological activities. So how to give some psychological methods to relieve the tension on the stage?

The author thinks that we can learn from the psychological tactics and reactions of athletes in various competitive competitions. Deng Yaping, the world table tennis champion, won 4 Olympic gold medals and 18 world championships in her sports career. Her "ruthlessness" on the field is well known. However, the audience only knows that she is a world champion, but they don't know that she was eliminated by the provincial team at the beginning of practicing playing. Even when she entered the selection of the national team, four of the five coaches expressed opposition, and only one coach was optimistic about her. However, how did she become a world champion step by step under the condition of not being optimistic?

Recently, Deng Yaping published a book called "the art of power". Through this book, we can deeply understand why Deng Yaping succeeded. In this book, she explains in detail her psychological tactics in various competitions over the years, especially in the Olympic Games. At the beginning of the book, a "Wallenda Effect" is mentioned. This effect comes from the famous American high-altitude tightrope walker Karl Wallenda, an excellent performer, unfortunately slipped and died in an important performance. Afterwards, his wife said, I know something will happen this time. Because he kept saying before playing, "This time is too important to fail". In the past, every successful performance, he always thought about walking a tightrope itself, regardless of everything it might bring. When reading this passage, the author remembered the scene of forgetting words as the host in a major performance a few years ago, and the psychological activities before the whole performance were almost the same as those of Wallenda. After the performance, I had a profound reflection, and realized that I didn't focus on the performance itself, but put too much energy into the performance results, but made mistakes. Therefore, when I saw the "Wallenda" effect, I instantly felt the same.

For table tennis, Deng Yaping is not a talented athlete because of her short stature. However, besides practicing hard, she is constantly thinking about how to turn her shortcomings into strengths. Coupled with her indomitable personality, training along the way is full of hardships and cruelty. But can you win the game as long as you practice hard? From the book "the art of power", we realize that when everything is in place, both sports competitions and stage performances need the support of "one east wind"-that is, psychological methods.

In the book "the art of power", Deng Yaping once mentioned that as an athlete in the competition field, he is not actually fighting for skills, because everyone's skills will not differ too much, but more is competing for whose heart is stronger. Bai Yansong, the famous host, said: Deng Yaping has a big the art of power. Deng Yaping also described in detail her psychological tactics with her 
opponents on the field. Sports, as a kind of competitive competition, has a similar psychological test with the presentation of performing arts on the stage. Therefore, in the stage performance, in addition to mastering solid basic skills and certain stage experience, we can also get some professional support from the psychological level, so as to make the stage performance of vocal music performers more targeted. The uncertain factors of stage performance bring great pressure to performers, and everyone's inner tolerance for pressure is closely related to talent and the raising process of nurturers. Therefore, some actors are born with "people come crazy", which means that the more such actors have an audience, the more excited he will be; However, some actors sing very well under the stage, and once they step onto the stage, they will be "distracted" or they will be too nervous to play normally when they encounter major performances. It can be seen that giving some scientific support from the psychological level will make many vocal music performers take fewer detours on the stage, and adapt to the stage faster or find countermeasures for their nervous mentality in time in major performances.

\section{The psychological coping methods of vocal music performers' nervousness in stage performance}

\subsection{The use of the art of power methods}

This method needs to preset a specific action in advance. For example, the "the art of power" method used by Deng Yaping on the field is to press the table three times; Fan Deng, the founder of Fan Deng Reading, relieved his nervousness in his speech by squeezing the water cup he carried with him. This method has been used by the author inadvertently. Once, in a short speech, a little tension suddenly hit. At that time, the author happened to be holding the microphone, so he shook the microphone with both hands very hard. In an instant, his heart returned to calm, and the language flowed out naturally. The applause of the speech on that day continued. Shortly after this incident, the author saw the method of "the art of power", only to think that he had inadvertently applied this method. Then I remembered a small scene in my past life. Once her daughter was ill and took her to an injection. When she arrived at the hospital, she avoided entering the injection room for various reasons. Later, after she could no longer find an excuse, she was carried to the injection window and got down. When the nurse's syringe quickly plunged into her little ass, she suddenly sang "English Alphabet Song", ABCDEFG...... All the people present were amused by her, and her daughter did not cry that day. At that time, the author didn't understand psychology and didn't have any concepts, so he didn't know that his daughter, who was over 2 years old, actually inadvertently and spontaneously applied "the art of power" in psychology. Now that I think about it, it was not that she didn't cry at that time, but that she used singing to transfer the pain caused by the injection.

The human brain responds to "prohibition" slower than "command". If you want to "stop thinking", you will only think more. The correct way is to improve your "distraction ability" and get rid of bad thoughts by diverting attention at an important juncture. According to the description of "the art of power" and the actual cases encountered in life, the author thinks that this method can be applied to the psychological adjustment of vocal music performers' stage performances, and it should be feasible and effective as long as their own "little moves" are preset in advance and practiced moderately.

\subsection{Positive self-encouragement}

The stage performance of vocal music performers can be said that every stage is unknown. On the basis of solving the sound technical problems and the familiarity of tracks in the early stage, we 
should also give ourselves some positive hints from the psychological level. For example, don't care too much about and think about what the performance results bring to you, but cheer yourself up in your heart and face your well-prepared singing calmly. No matter what happens during the performance, face it calmly without fear of failure. Failure is not terrible, but we should analyze the reasons with a positive attitude, so as to avoid repeating the same mistakes in the next performance. Sometimes failure is also a kind of growth. As long as you learn to take stock and summarize yourself, you can grow rapidly in a positive attitude and gradually adapt to the stage performance under intense pressure.

\subsection{Understanding of Jansen effect}

Jansen is an American speed skater and a top athlete in the world. However, he has missed the gold medal seven times in a row. Psychologists call this phenomenon, which usually performs well but falls off the chain at a critical juncture, "Jansen effect". Deng Yaping lost 3-1 to Japan's Koyama Chile in the Asian Games in Hiroshima in 1994. Like excellent athlete Zhan Sen, she didn't feel nervous. When reporters and coaches asked her if she was nervous, she felt the same as Zhan Sen. She didn't realize any nervousness and tried her best in the game.

Therefore, Deng Yaping summed up in her book: The Jansen effect is like an invisible wall, which everyone will encounter, but you can't predict when and where it will appear. We should accept this reality.

On the stage of vocal music performance, we will also encounter the phenomenon of "Jansen effect". When we understand the unpredictable uncertain factor of "Jansen effect", we only need to open our heart to accept failure and actively analyze the reasons in the way of growth thinking, so as to strive for better performance next time.

\subsection{Deliberate practice}

Dr. Andreas Eriksson, a professor of psychology at Florida State University, in his book Deliberate Practice, shows readers that so-called genius is actually a special skill achieved through purposeful deliberate practice. In fact, not all the successful people we see in life are very talented athletes. For example, Deng Yaping was once not favored because of her low stature. She was only 8 years old when she was eliminated by the provincial team. After being eliminated, her indomitable character forced her to practice deliberately for 10 hours every day. Michael Jordan, a familiar world superstar, was rejected by the team in high school. He once thought about giving up, but in the end, his love and indomitable spirit made him pay more sweat than others, so he had brilliant achievements in the future. Paganini, a world-famous violinist, once pulled down the whole song after breaking three strings in a row during a performance on stage. It is said that there was blood on his hands at that time. However, the audience didn't know that playing the whole song with one string was something he had deliberately practiced in the audience. It can be seen that deliberate practice with proper purposeful methods can help a person grow up on the professional road faster. As a vocal performer, you can also enhance your singing ability to adapt to the stage through various deliberate exercises.

To sum up, as a branch of stage performance, vocal music art, like other forms of artistic expression, will have uncertain factors. Therefore, whether it is an actor with excellent psychological quality or a student who is often prone to stage fright, mastering some psychological knowledge and methods, coupled with his excellent professional and technical level, can provide greater possibilities for the stable play in stage performances. At the same time, mastering certain ways and means to overcome mental tension can help most vocal performers find a way to adapt to the stage and relieve tension as soon as possible, so as to reduce the time to explore their own 
experience through continuous stage practice. Mastering excellent vocal singing skills, combined with psychological theory and effective means will help vocal music performers get twice the result with half the effort to find a better and stronger self on the stage.

\section{References}

[1] Deng Yaping Renmin. 2021. "The art of power" University of China Press

[2] Anders Ericsson Anders Erickson. 2021. "Deliberate Practice" Robert Pool Robert Poole translated by Wang Zhenglin Machinery Industry Press

[3] Zeng Xiaoan.n .d. "Stage Psychological Adjustment of National Singers" Journal "Research on National Art" [4] Seng Wenli. 2014. "On Psychological Adjustment of Vocal Music Stage Performance" From the Journal "Grand View of Music", No.12, 2014 